\title{
Influence of Industrial Heat Treatments on the Precipitation Kinetics of an Al-Cu-Mg-Ag-Zr Alloy
}

Muna Khushaim ${ }^{*}$ and Alexander Rothenberger

Physical Sciences and Engineering Division, King Abdullah University of Science and Technology (KAUST), Thuwal 23955-6900, Kingdom of Saudi Arabia

\begin{abstract}
The impact of different industrial heat treatments on the precipitation kinetics and phase transformation of an Al-Li alloy is studied. AA2195 (Al -1.69 at.\% Cu-3.87 at.\% Li-0.39 at.\% Mg-0.06 at.\% Ag-0.04 at.\% $\mathrm{Zr}$ ), a commonly used aluminum alloy, was selected as a model system in this study. Evaluation of the microstructure is performed using differential scanning calorimetry (DSC), transmission electron microscopy (TEM) and field ion microscopy (FIM). Three-dimensional atom probe tomography (APT) was utilized to investigate the intermetallic precipitates in the microstructure after applying T4, T8 and T6 heat treatment tempers. After conducting the T4 heat treatment, $\beta^{\prime}$ dispersoids were found to potentially act as nucleation sites for the $T_{1}$ phase. The segregation of $\mathrm{Li}$ and $\mathrm{Cu}$ to the $\beta^{\prime} /$ matrix interface is reported. The microstructure of the samples subjected to the T8 heat treatment exhibit the intersections of different $T_{1}$ platelets, which favor a mechanism to hinder the motion of dislocations, resulting in a high hardness value. Growth of the $T_{1}$ platelet which proceeds via a ledge mechanism and the dissolution of the $\theta^{\prime}$ phase were observed with increasing aging temperature. After conducting the T6 heat treatment, the microstructure predominantly consists of the $T_{1}$ phase. The nucleation of the $T_{1}$ platelets on $\mathrm{Mg}$ enriched regions that contain localized Ag atoms was observed, suggesting a potential role of $\mathrm{Mg}$ to enhance the nucleation of the $T_{1}$ phase.
\end{abstract}

\section{Introduction}

In response to the demands of various industries for light structural materials, different aluminum lithium alloys have been developed [1] These alloys are commonly selected because they exhibit an enhanced strength/weight ratio and therefore are typically applied as functional materials with high performance in the aerospace and automobiles industries. Economically, $\mathrm{Al}-\mathrm{Li}$ alloys are only three times as expensive as conventional aluminum alloys, whereas competing hybrid materials can be up to 10-30 times more expensive [2]. In the context of high fuel prices and fierce competition between composite, hybrid materials and aluminum alloys, different $\mathrm{Al}-\mathrm{Li}-\mathrm{Cu}$ alloys have been developed to overcome most of technical issues associated with the formerly available materials [3]. In the space industry, for instance, $\mathrm{Al}-\mathrm{Li}-\mathrm{Cu}$ based alloys are the candidate material for the construction of launchvehicle liquid-propellant tanks because the ductility and toughness of the alloy are not affected at the lower temperatures. These alloys are known to be strengthened through precipitation hardening and are attracting strong interest in the framework of the development of new alloys, particularly for aerospace components [4]. The current study selects one of the widely used Al-Li-Cu alloys from the Weldalite family [1], namely, the commercial AA2195. This alloy was developed to replace the AA2219 alloy, which was conventionally used in the US space shuttles [5]. The AA2195 is a weldable alloy of high strength that provided a considerable mass reduction and increase in the payload capacity of the space shuttle [5]. This class of alloy is able to achieve superior mechanical properties in the stretched and artificially aged condition (termed as T8), artificially aged condition (termed as T6) and naturally aged condition (termed as T4) [6].

Previous studies revealed that the $\mathrm{Al}$ alloys in $\mathrm{T} 4$ temper leads to strengthening by a combination of the G.P zone and $\delta^{\prime}\left(\mathrm{Al}_{3} \mathrm{Li}\right)$ precipitates [7]. The alloy in this temper displays a rapid and strong naturally aging response, even without prior cold working. For example, the tensile strength of Weldalite grade alloy in the T4 temper is $20 \%$ greater than that of the leading, weldable alloy AA2219 in the T87 temper [8].
The $\mathrm{Al}$ alloys with the $\mathrm{T} 6$ temper are reported to be strengthened primarily by the $T_{1}\left(\mathrm{Al}_{2} \mathrm{LiCu}\right)$ phase, with a minor presence of the $\theta^{\prime}\left(\mathrm{Al}_{2} \mathrm{Cu}\right)$ phase [9]. The alloy in this temper exhibited resistance to corrosion during the retrogressed and raged process [10]. This corrosion resistance can be explained in the terms of the coarsening of the grain boundary precipitates. In addition, the increase in the volume fractions of the second phase particles at the grain interiors was responsible for the increase in the strength of the alloy following this temper [11]. In addition, a two-step T6 aging treatment was demonstrated to result in strength and ductility comparable to those of samples in the T8 temper [10].

For the $\mathrm{Al}$ alloy in the $\mathrm{T} 8$ condition, the microstructure, as revealed by transmission electron microscopy, mainly consisted of the $\delta^{\prime}\left(\mathrm{Al}_{3} \mathrm{Li}\right)$ and $T_{1}\left(\mathrm{Al} \mathrm{L}_{2} \mathrm{CH}\right)$ precipitates as the primary strengthening phases [12]. The application of plastic deformation prior to artificial aging is used to promote a uniform distribution of heterogeneously nucleated $T_{1}$ precipitates. The distribution of the $T_{1}$ precipitates in the microstructure after conducting the T8 temper is considered to be responsible for the improvements in the strength and fracturetoughness. The plastic deformation can be effective for strengthening aluminum alloys processed at cryogenic and room temperatures.

In the quenched state and the early stage of aging, the microstructure shows a mixture of well-defined ordered $\delta^{\prime}\left(\mathrm{Al}_{3} \mathrm{Li}\right)$ and complex $\delta^{\prime}$ $\left(\mathrm{Al}_{3} \mathrm{Li}\right) / \beta^{\prime}\left(\mathrm{Al}_{3} \mathrm{Zr}\right)$ ordered precipitates with spherical and polygonal shapes in the Zr containing alloy [13]. After solution aging treatment,

${ }^{*}$ Corresponding Author: Muna Khusahim, Physical Sciences and Engineering Division, King Abdullah University of Science and Technology (KAUST), Thuwal 23955-6900, Kingdom of Saudi Arabia, Tel: +966503372178; E-mail: Muna.Khushaim@kaust.edu.sa

Citation: Khushaim M, Rothenberger A (2015) Influence of Industrial Heat Treatments on the Precipitation Kinetics of an Al-Cu-Mg-Ag-Zr Alloy. Int J Metall Mater Eng 1: 113. doi: http://dx.doi.org/10.15344/2455-2372/2015/113

Copyright: (C 2015 Khushaim et al. This is an open-access article distributed under the terms of the Creative Commons Attribution License, which permits unrestricted use, distribution, and reproduction in any medium, provided the original author and source are credited. 
most of the $\mathrm{Zr}$ are found within small spherical $\left(\mathrm{Al}_{3} \mathrm{Zr}\right)$ dispersoids that are approximately $20 \mathrm{~nm}$ in diameter [14].

The objective of this study is to investigate the dependence of the precipitation kinetics and the phase transformations in complex Al$\mathrm{Li}$ alloys on the preformed heat treatment conditions. AA2195, a commonly used aluminum alloy, was selected as a model system. The heat treatments considered in this study were common industrial heat treatments: T8 temper (solution treated, cold working and artificially aging), T4 temper (solution treated and naturally aging) and T6 temper (solution treated and artificially aging) [3]. The use of a combination of experimental methods - a laser-assisted wide angle tomographic atom probe (LAWATAP), field ion microscopy (FIM), transmission electron microscopy (TEM), differential scanning calorimetry (DSC) and Vickers micro hardness measurements - allowed for a qualitative evaluation of the precipitation kinetics and phase transformation as functions of the temper conditions.

\section{Experimental}

Plates of 1-mm thick alloy AA2195 were subjected to the following treatment conditions: 1 ) T8 (solution treatment for $1 \mathrm{~h}$ at $510^{\circ} \mathrm{C}$, water quenching, plastic deformation of $3 \%$ and artificial aging for $30 \mathrm{~h}$ at $150^{\circ} \mathrm{C}$ ), 2) $\mathrm{T} 4$ (solution treatment for $1 \mathrm{~h}$ at $530^{\circ} \mathrm{C}$, water quenching and natural aging at room temperature for $4000 \mathrm{~h}$ ), and 3) T6 (solution treatment for $2 \mathrm{~h}$ at $495^{\circ} \mathrm{C}$ and for $4 \mathrm{~h}$ at $515^{\circ} \mathrm{C}$, water quenching and artificial aging for $20 \mathrm{~h}$ at $180^{\circ} \mathrm{C}$ ). The chemical compositions of the samples following treatment under the $\mathrm{T} 8, \mathrm{~T} 4$ and $\mathrm{T} 6$ conditions are presented in Table 1 . The measured compositions using inductively coupled plasma optical emission spectrometry using an ICPOEC 720-ESinstrument are in a good agreement with the nominal composition in all cases.

The influence of different heat treatment conditions on the mechanical properties was studied using the Vickers hardness test. The samples were polished by using standard metallographic processes (grinding and polishing by using colloidal silica). Vickers micro-harness measurements were performed using a load of 0.2 $\mathrm{kg}$ applied on the samples for 10 seconds. The hardness values were determined by an average of 10 measurements.

DSC was performed at a heating rate of $10 \mathrm{~K} / \mathrm{min}$ in a Netzsch DSC $204 \mathrm{~F} 1$ aperture. The mass specimen between 12 and $16 \mathrm{mg}$ was placed in an $\mathrm{Al}$ crucible in a dynamic nitrogen atmosphere $(20 \mathrm{ml} /$ min). The thermal properties of AA2195 for different tempers were examined.

TEM analysis was performed after each specific treatment. Electrontransparent foils were grinded to an approximate thickness of $150 \mu \mathrm{m}$, mechanically punched, and then electro-polished by standard twinjet polishing using a solution of $20 \mathrm{vol} \%$ of nitric acid in methanol at $-20^{\circ} \mathrm{C}$. The analysis was performed using a JEOL $2100 \mathrm{~F}$ apparatus operated at $200 \mathrm{kV}$.
Microstructural characterization at the atomic scale was performed using atom probe tomography (APT). Atom probe studies were performed using both LAWATAP in the voltage mode at $30 \mathrm{~K}$ with a pulse fraction of $20 \%$ and at a vacuum level of $10^{-8} \mathrm{~Pa}$. Small rods of $(0.3 \mathrm{~mm} \times 0.3 \mathrm{~mm} \times 10 \mathrm{~mm})$ were spark machined from the bulk and then electro-polished to a sharp needle shaped specimen for APT analysis and FIM observation. Electro-polishing was performed using a solution of $30 \mathrm{vol} \%$ of nitric acid in methanol at $-20^{\circ} \mathrm{C}$ in the range of 5 to 7 V. FIM images were obtained on LAWATP using Ne as the imaging gas at $25 \mathrm{~K}$ and $1.2 \times 10^{-3} \mathrm{~Pa}$.

The obtained APT data were visualized using the TAP3D and IVAS software programs provided by Cameca. Calibration of the main reconstruction parameters was performed by observing the atomic plane for the respective crystallographic pole. The composition of the different observed precipitates was measured quantitatively using the proximity histogram (prixogram) technique [17]. In this methodology, an isoconcentration surface first delineates the precipitates. Next, starting at the isoconcentration surface, which is the origin of the proxigram, and then moving toward the center of precipitates (positive distance), the composition of the precipitate is measured according to discrete shells with the shape of isoconcentration surface at fixed intervals. The proxigrams in this study were selected with a spacing of $0.1 \mathrm{~nm}$ between these shells. The matrix composition is obtained by starting at the isoconcentration surface and moving into the matrix (negative distance).

\section{Results and Discussions}

\section{Hardness curves}

Figure 1 shows the hardness evolution during the heat treatment of the alloy for different temper conditions: T4, T8 and T6. The first feature of interest is that the specimen in $\mathrm{T} 8$ temper has a higher hardness $((160.3 \pm 7) \mathrm{HV} / 1.96)$ than those of the specimens in the T4 and T6 tempers. During T4 and T6 tempering, both specimens experience a significant and quite similar hardening response. The minimum hardness value is reached in T6 tempering $((112 \pm 5)$ HV/1.96). During the natural aging of the sample in the T4 temper, no significant change of hardness is observed ((125.2 \pm 9$) \mathrm{HV} / 1.96)$. This behavior can be attributed to the presence of different nano-scale structural features after the conducting of each heat treatment temper. The explanation of most of these features from the microstructure evaluation will be presented in the following section.

\section{TEM analyses}

TEM analysis of the specimens conducting different temper conditions is shown in Figure 2. The microstructure of a naturally aged sample after conducting the T4 heat treatment is shown in Figure 2a.Precipitates were characterized using an exact [110] zone. The microstructure encompasses spherical precipitates with $\mathrm{L} 1_{2}$ structure. A schematic of the indexed selected area diffraction pattern (SADP)

\begin{tabular}{|l|l|l|l|l|l|l|}
\hline Alloying element & $\mathrm{Cu}$ & $\mathrm{Li}$ & $\mathrm{Mg}$ & $\mathrm{Ag}$ & $\mathrm{Zr}$ & $\mathrm{Al}$ \\
\hline Nominal (wt. \%) & 4 & 1 & 0.36 & 0.28 & 0.14 & 94.22 \\
\hline Nominal (at. \%) & 1.69 & 3.87 & 0.39 & 0.06 & 0.04 & 93.95 \\
\hline ICP - T8 (at. \%) & $1.74 \pm 0.19$ & $3.67 \pm 0.05$ & $0.36 \pm 0.01$ & $0.08 \pm 0.02$ & $0.04 \pm 0.0004$ & $94.11 \pm 0.27$ \\
\hline ICP - T4 (at. \%) & $1.55 \pm 0.1$ & $4.23 \pm 0.1$ & $0.31 \pm 0.04$ & $0.08 \pm 0.01$ & $0.04 \pm 0.0001$ & $93.79 \pm 0.25$ \\
\hline ICP - T6 (at. \%) & $1.58 \pm 0.1$ & $3.36 \pm 0.1$ & $0.3 \pm 0.03$ & $0.08 \pm 0.01$ & $0.04 \pm 0.0001$ & $94.64 \pm 0.24$ \\
\hline
\end{tabular}

Table 1: Chemical composition of alloying elements in AA2195. 
Citation: Khushaim M, Rothenberger A (2015) Influence of Industrial Heat Treatments on the Precipitation Kinetics of an Al-Cu-Mg-Ag-Zr Alloy. Int J Metall Mater Eng 1: 113. doi: http://dx.doi.org/10.15344/2455-2372/2015/113

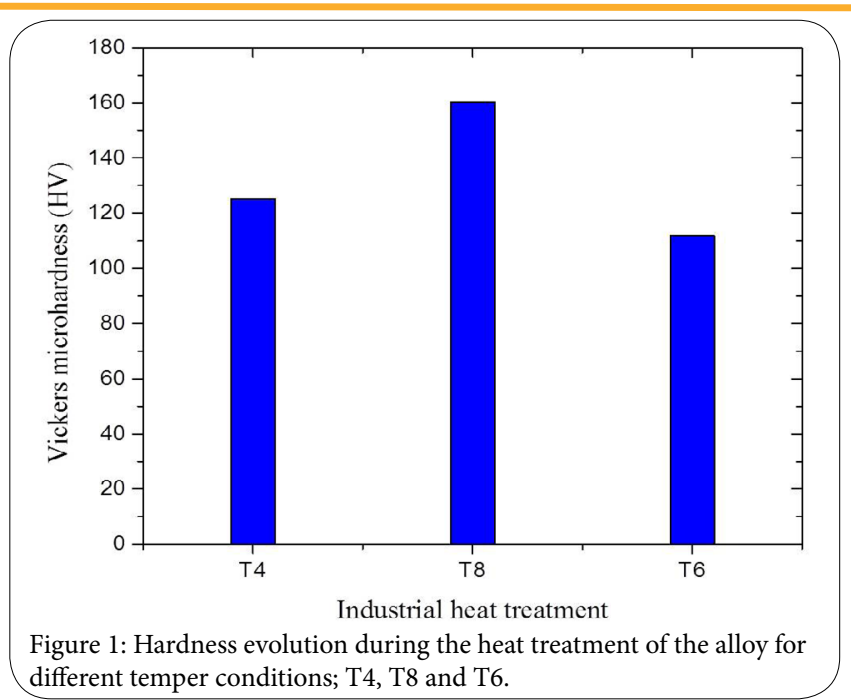

in the [101] direction is integrated with the bright field TEM image (Figure 2a). This observation indicates the presence of the supper lattice reflection, which originates from an $\mathrm{Ll}_{2}$ ordered structure representing $\beta^{\prime}\left(\mathrm{Al}_{3} \mathrm{Zr}\right)$ precipitates. The $\mathrm{L}_{2}$ unit cell is based on the face center cubic ( $f(c)$ structure of aluminum. However, the corner atoms are replaced by $\mathrm{Zr}$ atoms. This substitution means that all $\langle 100\rangle$ directions are super structure directions. The spherical precipitates are assigned to be of the $\beta^{\prime}$-type and not of the $\delta^{\prime}$-type because the Li composition in the investigated alloy is less than 5 at.\% (Table 1). Hence, there is no expectation to observe $\delta^{\prime}\left(\mathrm{Al}_{3} \mathrm{Li}\right)$ precipitates. However, the contrast of the spherical particles indicates that there are wings of low intensity surrounding the $\beta^{\prime}$ particles. This observation. could be due to the role of the $\beta^{\prime}$ phase on providing heterogeneousnucleation sites for the $\delta^{\prime}$ phase or/and $T_{1}$ phase $[18,19]$.
Figure $2 \mathrm{~b}$ shows a TEM bright field image of the specimen conducting T8 heat treatment condition. The image revealed a complex microstructure, including different precipitates with platelets and spherical morphology. Once again, precipitates were characterized using an exact [110] zone. A schematic of the indexed selected area diffraction pattern in the [101] direction in Figure $2 \mathrm{~b}$ indicates the presence of two variants of the $T_{1}$ precipitates as streaks along the $<111>$ directions in the pattern. The other two variants of this phase produce spots adjacent to the $\langle 200\rangle$ positions. The streaks along the $<200>$ directions reveal the presence of the $\theta^{\prime}$ precipitates. The super lattice reflection in the pattern is attributed to the $\beta^{\prime}$ precipitates. These observations provide evidence that the peak hardness microstructure consisted of the thin $T_{1}$ platelets associated with the smaller fraction of $\mathrm{Cu}$-rich phase, i.e., $\theta^{\prime}$ platelets.

A TEM bright field image of the specimen after the T6 heat treatment is shown in Figure $2 \mathrm{c}$. In this case, the matrix contained the $T_{1}$ precipitates as the primary strengthening phase. It is difficult to observe any streaks along $<200>$ directions, due to a negligible presence of the $\theta^{\prime}$ precipitates in the microstructure for the specimen under the T6 condition. However, it is clear from Figure $2 c$ that under T6 heat treatment the $T_{1}$ precipitates remain quite thin and in a good dispersion.

\section{DSC analysis}

Further confirmation of the precipitation kinetics during different temper treatments was obtained by performing DSC scans for the specimens under the T4, T8 and T6 conditions. The results of the thermal characterizations are shown in Figure 3, which presents the DSC traces of the specimens in all three temper treatments. The precipitate and dissolution reactions important for thermal stability and precipitation occur in the aluminum alloy in the range of temperature of $25-350^{\circ} \mathrm{C}$ [12].

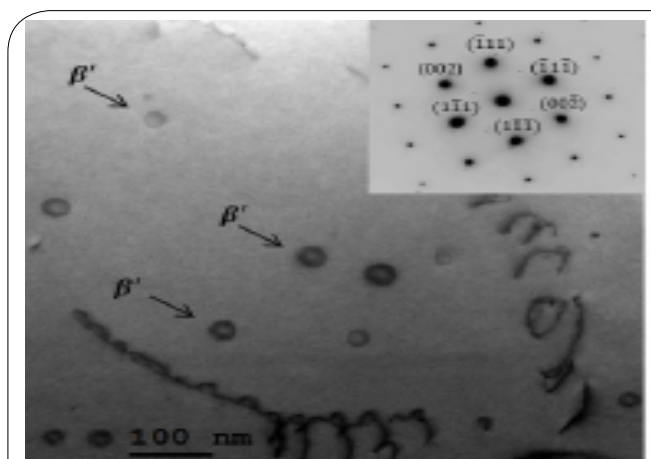

(a)

(b)

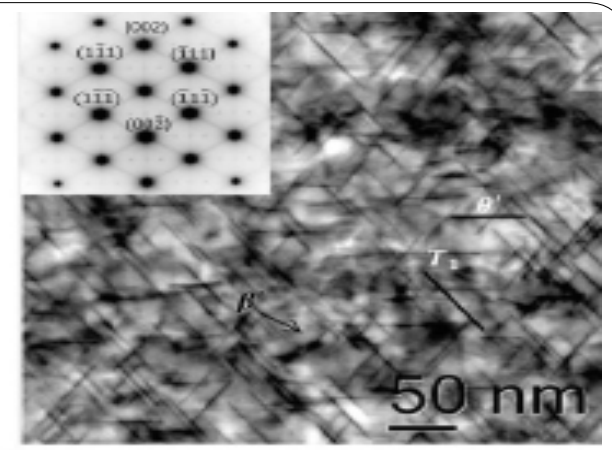

(c)

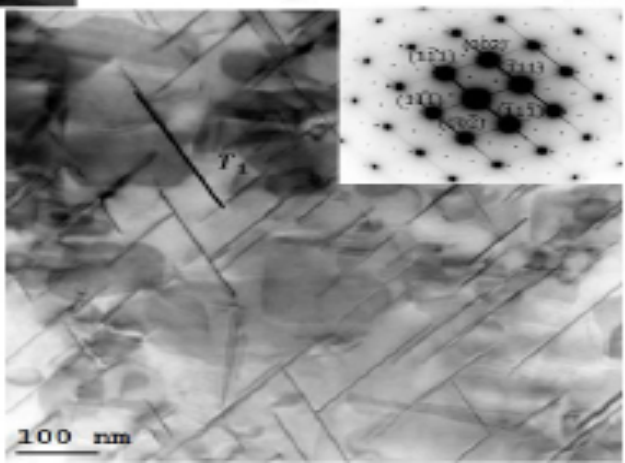

Figure 2: Evolution of the microstructure as observed by TEM. (a) Typical bright field image of the specimen after conducting the T4 heat treatment shows the presence of $\beta^{\prime}$ precipitates within the microstructure and the corresponding [101] selected area diffraction pattern (SADP). (b) Bright field image of the microstructure conducting T8 heat treatment condition shows a complex microstructure with the $T_{1}, \theta^{\prime}$ and $\beta^{\prime}$ precipitates and the corresponding [101] selected area diffraction pattern (SADP). (c) Microstructure of the specimen after the T6 heat treatment condition consists of $T_{1}$ precipitates as the primary strengthening phase and the corresponding [101] selected area diffraction pattern (SADP). 


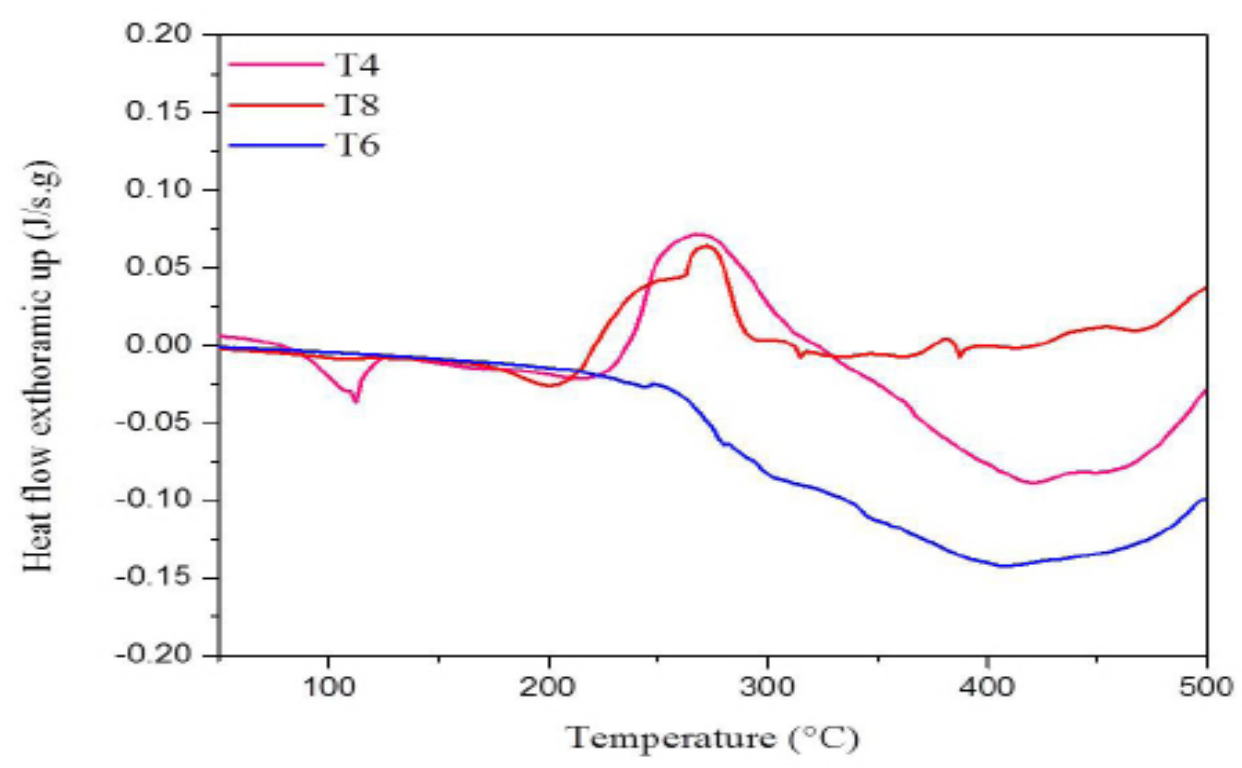

Figure 3: DSC traces of the specimens in three temper treatments; T4, T8 and T6.

The major thermal events for the specimens in the T8 condition are the endothermic dissolution peak spanning the range of $\sim 180-$ $220^{\circ} \mathrm{C}$ and the exothermic precipitation peak spanning the range of $\sim 220-280^{\circ} \mathrm{C}$. For the specimen in the T4 condition, the DSC signal shows the presence of two endothermic dissolution peaks: the first peak spanning the range of $\sim 90-130{ }^{\circ} \mathrm{C}$ and the second spanning the range of $\sim 190-230^{\circ} \mathrm{C}$. Moreover, the presence of an exothermic precipitation peak spanning the range of $\sim 230-310^{\circ} \mathrm{C}$ and an endothermic dissolution peak spanning the range of $\sim 320-500^{\circ} \mathrm{C}$ are observed. Finally, the signal for the specimen in the T6 condition shows an endothermic dissolution peak at elevated temperature spanning the range of $\sim 320-500^{\circ} \mathrm{C}$.

Based on previous observations in the literature [12] and on the TEM analyses above, the peaks can be identified as the following. The endothermic dissolution peak spanning the range of $\sim 90-130^{\circ} \mathrm{C}$ in the T4 condition is the result of dissolution of the GP zone (precursor of the $\theta^{\prime}$ phase). The second endothermic dissolution peak spanning the range of $\sim 190-230^{\circ} \mathrm{C}$ is due to the dissolution of the $T_{1}$ phase. The exothermic precipitation peak spanning the range of $\sim 230-310^{\circ} \mathrm{C}$ is due to the precipitation of the $\theta^{\prime}$ phase. Finally, the lastendothermic dissolution peak spanning the range of $\sim 350-500^{\circ} \mathrm{C}$ corresponds to the dissolution of the existing bulk phases [20].

For the T8 condition, the endothermic dissolution peak spanning the range of $\sim 180-220^{\circ} \mathrm{C}$ is assigned to the dissolution of the $T_{1}$ phase. However, the exothermic precipitation peak spanning the range of $\sim 220-280^{\circ} \mathrm{C}$ is assigned to the re-precipitation of the $T_{1}$ phase again. The re-precipitation phenomena under the dynamic heating condition in DSC have been previously reported for underaged Al-Li alloys [21]; the authors reported the retrogression of the $\delta^{\wedge}$ ' phase, which formed during the aging process, and the subsequent exothermic peak, which corresponds to the re-precipitation of the $\delta$ phase, were explained in terms of the increase in the number of the solute atoms in super saturated solid solution, which causes the reprecipitation to occur. In our case, the strong re-precipitation of the $T_{1}$ phase observed for the specimen in $\mathrm{T} 8$ condition suggests that the T8 temper condition still exhibits an appreciable super saturation with respect to $\mathrm{Cu}$ and $\mathrm{Li}$ atoms. During the DSC scan with a heating rate of $10 \mathrm{~K} / \mathrm{min}$, this super saturation leads to the precipitation of an additional amount of the $T_{1}$ phase [20].

Finally, the endothermic dissolution peak spanning the range of $320-500^{\circ} \mathrm{C}$ in the $\mathrm{T} 6$ condition most probably originates from on going $\mathrm{T}_{1}$ dissolution, which is considered to be the dominant phase in the microstructure, according to the TEM image (Figure 2c).

The variations and the similarities of the thermogram curves in Figure 3 reveal the changes of precipitation processes to some extent. It is worth to note that the identification of the precipitation kinetics and phase transformations has not been conclusively established by the DSC signals. Therefore, obtaining a clear picture of the precipitation kinetics and phase transformations from the naturally aged condition (T4) to the peak-aged state (T8) and then to the slightly over-aged state (T6) required a deeper insight into the microstructure-properties relationship at the nano-scale using a global characterization technique, such as APT.

\section{FIM observation}

Prior to performing the APT analysis, the FIM mode in the LAWATAP was used. FIM was mainly used to develop the needle shaped samples for the subsequent analysis by APT. Surface oxide and damage induced by using the standard electro-polishing method could thus be eliminated. In this method, Ne gas atoms are field ionized due to the presence of a high electric field at the tip surface. The ions of the image gas are then projected onto the imaging screen, where they form a highly magnified image of the surface [22].

Figure 4 shows the field ion micrographs for the alloy AA2195 after conducting the three industrial heat treatments, i.e., the T4, T8 and T6 conditions. Figure $4 \mathrm{a}$ is the field ion micrograph for the sample undergoing the T4 heat treatment condition. This Figure revealed the presence of the spherical precipitates, which appear bright in the images. These spherical precipitates are most probably of the $\beta$ '-type, as discussed above. Figure $4 \mathrm{a}$, also clearly shows that the contrast within the matrix is very poor and that the $\mathrm{Zr}$-rich precipitates appear very bright with respect to the $\operatorname{dim} \mathrm{Al}$ matrix. This observation is due to the higher evaporation field of $\mathrm{Zr}(56 \mathrm{~V} / \mathrm{nm})$ compared to that 
Citation: Khushaim M, Rothenberger A (2015) Influence of Industrial Heat Treatments on the Precipitation Kinetics of an Al-Cu-Mg-Ag-Zr Alloy. Int J Metall Mater Eng 1: 113. doi: http://dx.doi.org/10.15344/2455-2372/2015/113

Page 5 of 8
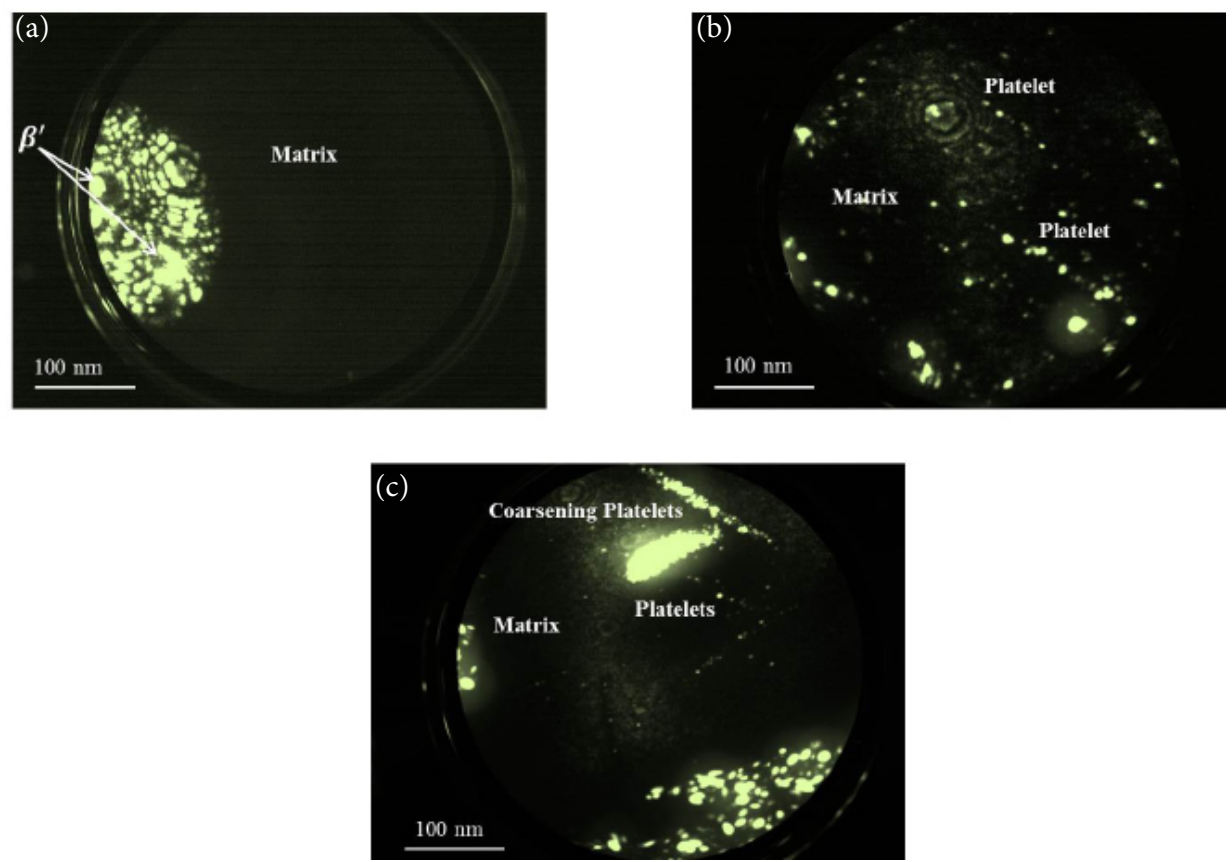

Figure 4: Field ion micrographs for the alloy AA2195 after conducting the three industrial heat treatments, the (a) T4, (b) T8 and (c) T6 conditions (All of the precipitates are brightly imaged).

of $\mathrm{Al}(19 \mathrm{~V} / \mathrm{nm})$ [23]. The difference on the microstructure after undergoing the T8 heat treatment condition is shown in Figure 4b. The presence of platelet shaped precipitates distributed within the matrix around the crystallographic pole that appear bright in the image is revealed. The microstructure of the sample under the T6 heat treatment condition is shown in Figure 4c. Once again, the sample consisted of platelet shaped precipitates. However, some of these platelets exhibit a slight coarsening behavior.

It is notable that all of the precipitates in this study are brightly imaged using the FIM mode. This observation can be explained by considering the field strengths of the existing precipitates, which contain $\mathrm{Cu}, \mathrm{Li}$ and $\mathrm{Zr}$, which are higher than that of the matrix, which is $\mathrm{Al}$ enriched. Accordingly, it is very likely in the FIM images that these precipitation regions protrude over the $\mathrm{Al}$ matrix and thus act as potential sites for imaging ions. This effect, in turn, causes the bright appearance of the precipitates in the micrographs [23].

\section{APT analysis}

The ternary Al-Li-Cu system has a complex precipitation sequence, exhibiting aspects of both binary $\mathrm{Al}-\mathrm{Cu}$ and $\mathrm{Al}-\mathrm{Li}$ systems. This precipitation is further complicated by the addition of minor alloying elements, such as $\mathrm{Mg}, \mathrm{Ag}$ and $\mathrm{Zr}$. The aging of this complex alloy generates a number of different phases. A detailed and robust investigation of the precipitation kinetics and complex phase transformations are discussed below.

\section{Naturally aged samples for the T4 temper}

Figure 5 shows the reconstructed volume of the sample in the T4 condition analyzed using LAWATAP. Based on the TEM and FIM observations above, the microstructure in this condition is expected to have only particles of $\beta^{\prime}\left(\mathrm{Al}_{3} \mathrm{Zr}\right)$. Due to the fact of the large diameter $(\sim 20 \mathrm{~nm})[14]$ and low number density of the $\beta^{\prime}$ phase in the microstructure, the APT analysis of such a phase is challenging. However, repeating the experimental analyses for the specimens in this condition permits the collection of two datasets, from which a statistically significant conclusion regarding this phase and its interface with the matrix are drawn.

Estimation of the $\beta^{\prime}$ precipitates was performed using a cluster identification algorithm [24]. $\mathrm{Zr}$ containing precipitates were identified by applying a maximum separation distance of $0.7 \mathrm{~nm}$ between the $\mathrm{Zr}$ atoms, with a minimum of $20 \mathrm{Zr}$ atoms in each precipitates. Exploration of the distribution of the $\beta^{\prime}$ precipitates isshown in Figure $5 \mathrm{a}$. The precipitates exhibit a somewhat spherical shape, with an average diameter of $(10 \pm 2) \mathrm{nm}$. The precipitates are then delineated by 5 at. $\% \mathrm{Zr}$ isoconcentration surface. A proxigram composition profile from this isoconcentration surface gives the chemical composition of the $\beta^{\prime}$ phase as $(23 \pm 2)$ at. $\% \mathrm{Zr},(1.8 \pm 0.5)$ at.\% $\mathrm{Li},(1.6 \pm 0.4)$ at.\% $\mathrm{Cu}(0.25 \pm 0.1)$ at.\% $\mathrm{Mg}$ and $(0.4 \pm 0.2)$ at.\% $\mathrm{Ag}$ with an $\mathrm{Al} / \mathrm{Zr}$ ratio close to 3:1 (Figure 5b). This result, also in a good agreement with the results reported by Sha and Cerezo [25], indicates precipitation of $\beta^{\prime}\left(\mathrm{Al}_{3} \mathrm{Zr}\right)$.

The presence of $\beta^{\prime}$ particles in the microstructure of the naturally aged sample can be interpreted as a result of the formation of $\beta^{\prime}$ dispersoids from the super saturations. These $\beta^{\prime}$ dispersoids are very stable due to the low $\mathrm{Zr}$ solubility in the Al matrix, i.e., a small misfit and sluggish diffusion of $\mathrm{Zr}$ [15]. $\mathrm{Zr}$ is considered to be an important trace alloying element in a high strength $\mathrm{Al}$ alloy. $\mathrm{Zr}$ is often added to optimize the properties of the alloy and has different effects, such asrefining the grain size, inhibiting the recrystallization and improving the corrosion cracking resistance [26] and quench sensitivity of the alloy [21]. To date, the ability of the main alloying elements, such as $\mathrm{Li}, \mathrm{Cu}, \mathrm{Mg}$ and $\mathrm{Ag}$, to be dissolved into these particles remains unclear [25]. The alloying elements of $\mathrm{Zr}, \mathrm{Li}, \mathrm{Cu}, \mathrm{Mg}$ and $\mathrm{Ag}$ are displayed separately in the top view of the reconstructed volume in Figure $5 c$. Clearly, inspection of this figure reveals the enrichment of the $\beta^{\prime} /$ matrix interface with $\mathrm{Li}, \mathrm{Cu}$ and $\mathrm{Mg}$ atoms, as indicated by the arrows. However, the enrichment of $\mathrm{Li}$ and $\mathrm{Cu}$ is more pronounced than that of other solute atoms. To quantify the enrichment of 
(a)

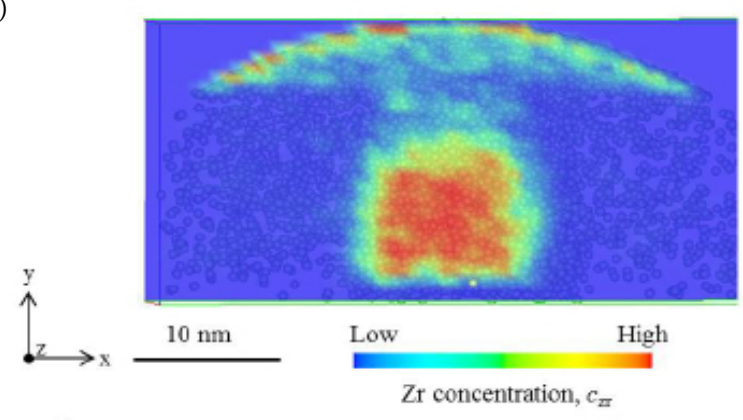

(c)
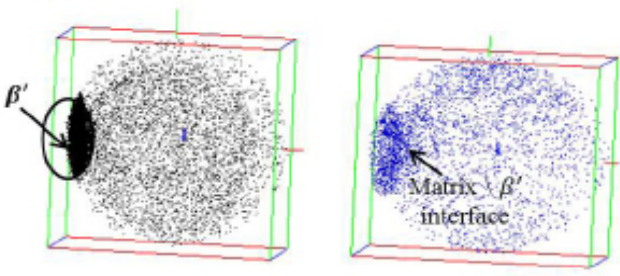

(b)

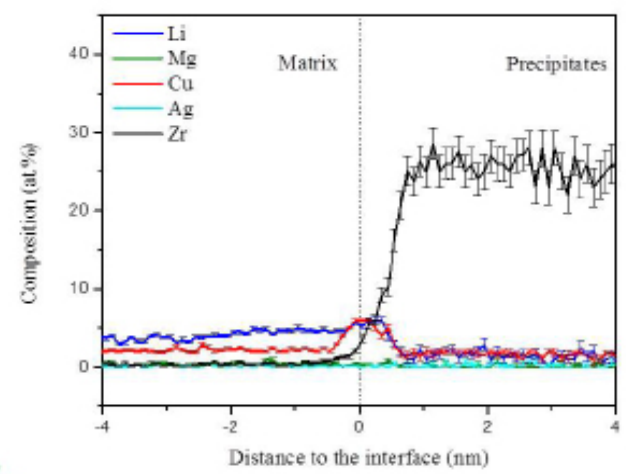

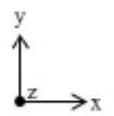
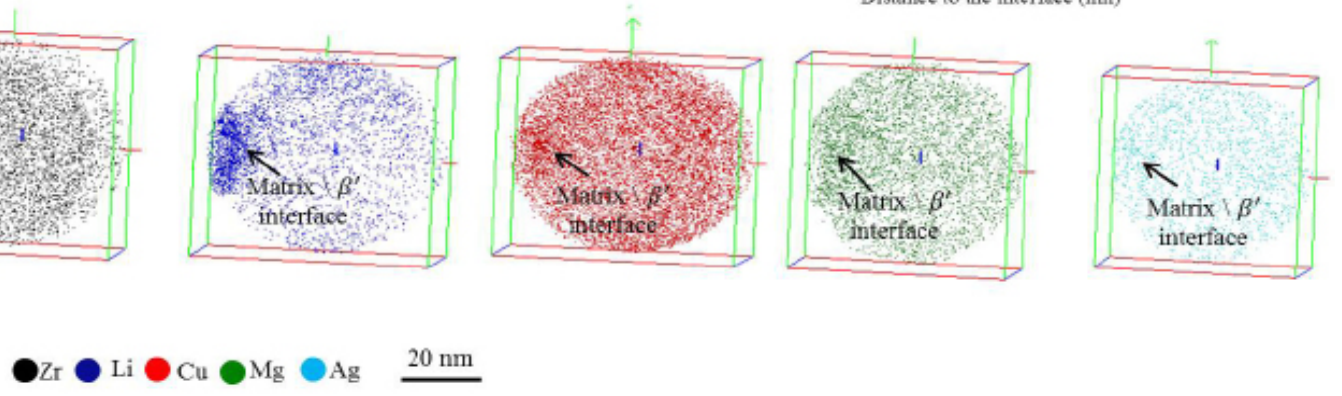

Figure 5: The reconstructed volume of the sample in the T4 condition analyzed using LAWATAP. (a) Exploration of the distribution of the $\beta$ ' precipitates in an Al matrix with an average diameter of $(10 \pm 2) \mathrm{nm}$, and high $\mathrm{Zr}$ concentration in its core.(b) A proxigram composition profile from the isoconcentration surface of 5 at. $\% \mathrm{Zr}$ gives the chemical composition of the $\beta^{\prime}$ phase as $(23 \pm 2)$ at. $\% \mathrm{Zr},(1.8 \pm 0.5)$ at. $\% \mathrm{Li},(1.6 \pm 0.4)$ at. $\% \mathrm{Cu}(0.25 \pm 0.1)$ at. $\% \mathrm{Mg}$ and $(0.4$ $\pm 0.2)$ at. $\% \mathrm{Ag}$ with an $\mathrm{Al} / \mathrm{Zr}$ ratio close to 3:1. (c) The top view of the reconstructed volume displays separately the alloying elements: $\mathrm{Zr}$, Li, Cu, $\mathrm{Mg}$ and $\mathrm{Ag}$. The figure indicates the segregation behavior of solute atoms at the $\beta^{\prime} /$ matrix interface.

the $\beta^{\prime} /$ matrix interface by solute atoms, the composition profile is drawn in the cylinder perpendicular to the interface. According to this profile, the compositions of $\mathrm{Li}$ and $\mathrm{Cu}$ atoms at the interface show an increase of approximately 2 at. \% and 5 at.\%, respectively. However, it seems that $\mathrm{Mg}$ atoms concomitantly segregated with $\mathrm{Li}$ and $\mathrm{Cu}$ atoms, whereas Ag did not. This observation, in combination with the TEM image (Figure 2a), indicates the strong segregation behavior of the $\mathrm{Li}$ and $\mathrm{Cu}$ atoms at the interface. This segregation suggests that $\beta$ particles possibly favor preferred nucleation sites for the $\delta^{\prime}$ phase or/ and $T_{1}$ phase. As the Li content in the investigated alloy is less than 5 at.\%, the presence of the $\delta^{\prime}$ phase is not expected. On this basis, it can be concluded that $\beta^{\prime}$ dispersoids play a potential role as heterogeneous nucleation sites for the $T_{1}$ phase in the naturally aged sample.

The good hardness response for this particular temper can be attributed to the presence of $\beta^{\prime}$ dispersoids, which is considered to be one of the hardening phases in a quenched sample [27]. Moreover, natural aging promotes a diffusion and segregation of solute atoms at the $\beta^{\prime} /$ matrix interface. This segregation behavior can be quantified using the APT method, as described above.

\section{Cold working and artificially aging of the samples at T8 temper}

To provide a qualitative assessment of the effect of the heat treatment condition on the precipitation kinetics and phase transformation through the transition from naturally aging condition to peak state aging, an APT analysis for the sample following T8 heat treatment was performed (Figure 6). Areas of higher $\mathrm{Cu}$ concentrations are visible in Figure 6a. Isoconcentration surfaces, which delineate regions containing more than 4 at. $\% \mathrm{Cu}$, are included to aid in the visualization of the $\theta^{\prime}$ precipitates with platelet morphology, an average diameter of $(1.8 \pm 0.2) \mathrm{nm}$ and an average length of $(11 \pm 1) \mathrm{nm}$. Figure $6 \mathrm{~b}$ shows a combined proxigram concentration profile based on the isoconcentration surfaces of all of the highlighted $\theta^{\prime}$ precipitates.
Starting at the matrix/precipitate heterophase interface and moving into the precipitate, the chemical composition was determined to be $(29.6 \pm 1)$ at. $\% \mathrm{Cu},(3.2 \pm 0.4)$ at.\% $\mathrm{Li}$ and $(1 \pm 0.2)$ at. $\% \mathrm{Mg}$. Concomitantly, the Li concentration inside the precipitates was found to be the same as its value in the matrix. This observation indicates the partitioning of the $\mathrm{Li}$ atoms within the $\theta^{\prime}$ precipitates, as shown in Figure 6a. The partitioning of $\mathrm{Li}$ atoms to the $\theta^{\prime}$ precipitates might indicate the possible occurrence of the phase transformation of the $\theta$ precipitates at the later stages of the aging. Given its importance for strengthening $\mathrm{Al}$, a large number of studies of the $\mathrm{Al}-\mathrm{Cu}$ precipitation sequence have focused on the properties of metastable $\theta^{\prime}[28,29]$. Relatively little is known concerning the compositional evolution of $\theta^{\prime}$ precipitates because its nanometer-scale platelet-like morphology makes quantitative analytical electron microscopy analyses extremely difficult. A recent study by Biswas et al. [30] shows that $\theta^{\prime}$ precipitates are observed upon aging between $190^{\circ} \mathrm{C}$ and $260^{\circ} \mathrm{C}$ in binary $\mathrm{Al}-1.7$ at.\% Cu alloys. They observed that after aging the alloy for $8 \mathrm{~h}$ at $190^{\circ} \mathrm{C}$, $\theta^{\prime}$ precipitates exhibit a range of $\mathrm{Cu}$-deficient core concentration that differ from the equilibrium composition of $\left(\mathrm{Al}_{2} \mathrm{Cu}\right)$. In contrast, alloys aged at $260^{\circ} \mathrm{C}$ for $4 \mathrm{~h}$ exhibited precipitates with $\mathrm{Cu}$ core concentrations close to the equilibrium value. According to the authors, the cause of the $\mathrm{Cu}$ deficiency in the $\theta^{\prime}$ precipitates at the lower aging temperature remains an open issue. In our study, the applied T8 heat treatment implies an artificially aging of the alloy for $30 \mathrm{~h}$ at $150^{\circ} \mathrm{C}$. This aging temperature is below the metastable solvus boundary for the $\theta^{\prime}$ precipitates in Al-Cu phase diagram [31], which justifies the presence of the $\theta^{\prime}$ phase in the microstructure. The agreement of our compositional analysis of the $\theta^{\prime}$ platelet with the expected stoichiometric composition of $\left(\mathrm{Al}_{2} \mathrm{Cu}\right)$ can be explained by considering the enhanced $\mathrm{Cu}$ diffusion to the existing defects in the microstructure with aging. Increase aging time results in a core concentration close to the equilibrium one. 
Citation: Khushaim M, Rothenberger A (2015) Influence of Industrial Heat Treatments on the Precipitation Kinetics of an Al-Cu-Mg-Ag-Zr Alloy. Int J Metall Mater Eng 1: 113. doi: http://dx.doi.org/10.15344/2455-2372/2015/113

(a)

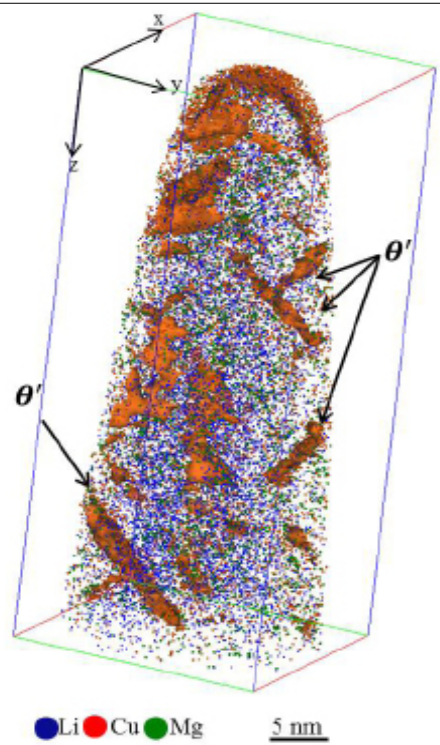

(b)

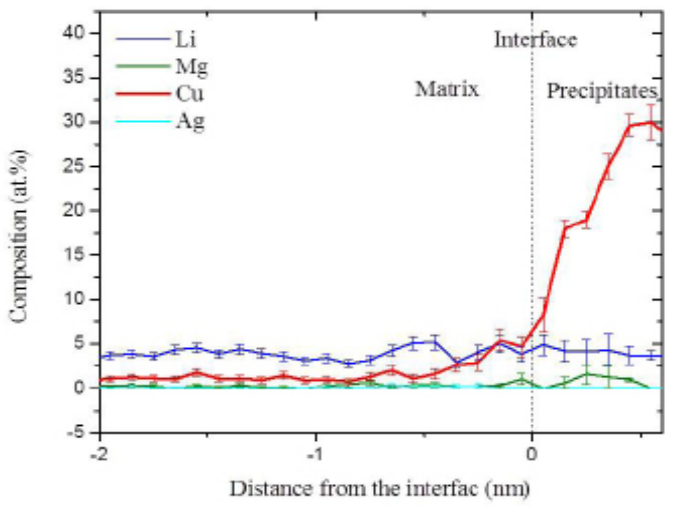

Figure 6: LAWATAP analysis of the sample following T8 heat treatment. (a) The reconstructed volume of the sample displayed with isoconcentration surfaces of 4 at.\% $\mathrm{Cu}$ delineate $\theta^{\prime}$ precipitates. (b) Corresponding combined proxigram composition profile based on these isoconcentration surfaces indicating a chemical composition of the $\theta^{\prime}$ precipitates as $(29.6 \pm 1)$ at. $\% \mathrm{Cu},(3.2 \pm 0.4)$ at. $\% \mathrm{Li}$ and $(1 \pm 0.2)$ at. $\% \mathrm{Mg}$.

In addition to the $\theta^{\prime}$ precipitates, a variety of the $T_{1}$ platelet The observed microstructure and good mechanical properties at precipitates are found within the microstructure (Figure 7). This observation is consistent with the reported result by Decreus et al. [32], who proposed that the pre-deformation process mostly promotes the formation of the $T_{1}$ phase, which is associated with the precipitates from the $\mathrm{Al}-\mathrm{Cu}$ binary system, i.e., the $\theta^{\prime}$ phase. Note the fine distribution of the $T_{1}$ platelets with an average thickness of $(1.4 \pm 0.2)$ $\mathrm{nm}$ and an average length of $(11.8 \pm 2) \mathrm{nm}$ within the microstructure (Figure 7a). Moreover, the intersection of more thantwo platelets, as indicted by the lines in Figure 7a, can be observed. These reported observations in this temper condition can be attributed to the applied plastic deformation prior to the artificial aging. The plastic deformation results in a high dislocation density, which results in a high density of nucleation sites for the $T_{1}$ and $\theta^{\prime}$ platelets and the presence of a high initial vacancy flux, which leads to the enhanced diffusion of the solute atoms. this temper confirm that applying plastic deformation accelerates the precipitation kinetics by approximately one order of magnitude [33]. Quantitative evaluations of the $T_{1}$ platelets precipitates presentedin Figure $7 \mathrm{~b}$ show that the average chemical composition, as estimated from the concentration composition profile based on the isoconcentration surface that contains more than 6 at.\% $\mathrm{Li}$ (calculated over 20 precipitates containing in different reconstructed volumes), is $(13 \pm 1)$ at. $\% \mathrm{Li},(11 \pm 1)$ at. $\% \mathrm{Cu},(3 \pm 1)$ at. $\% \mathrm{Mg}$ and $(1.5 \pm 0.4)$ at.\% Ag. This value shows a deviation from the $\left(\mathrm{Al}_{2} \mathrm{LiCu}\right)$ stoichiometry of the bulk $T_{1}$ phase and the enrichment of this phase with $\mathrm{Mg}$ and $\mathrm{Ag}$. The reason behind the deviation from the $\left(\mathrm{Al} \mathrm{LiCu}_{2}\right.$ stoichiometry has been reported in different studies [34,35]. The enrichment of the $T_{1}$ platelets with $\mathrm{Mg}$ and Ag play an important role in the high harness value for the specimen in this condition. By considering the current model proposed by Cassada
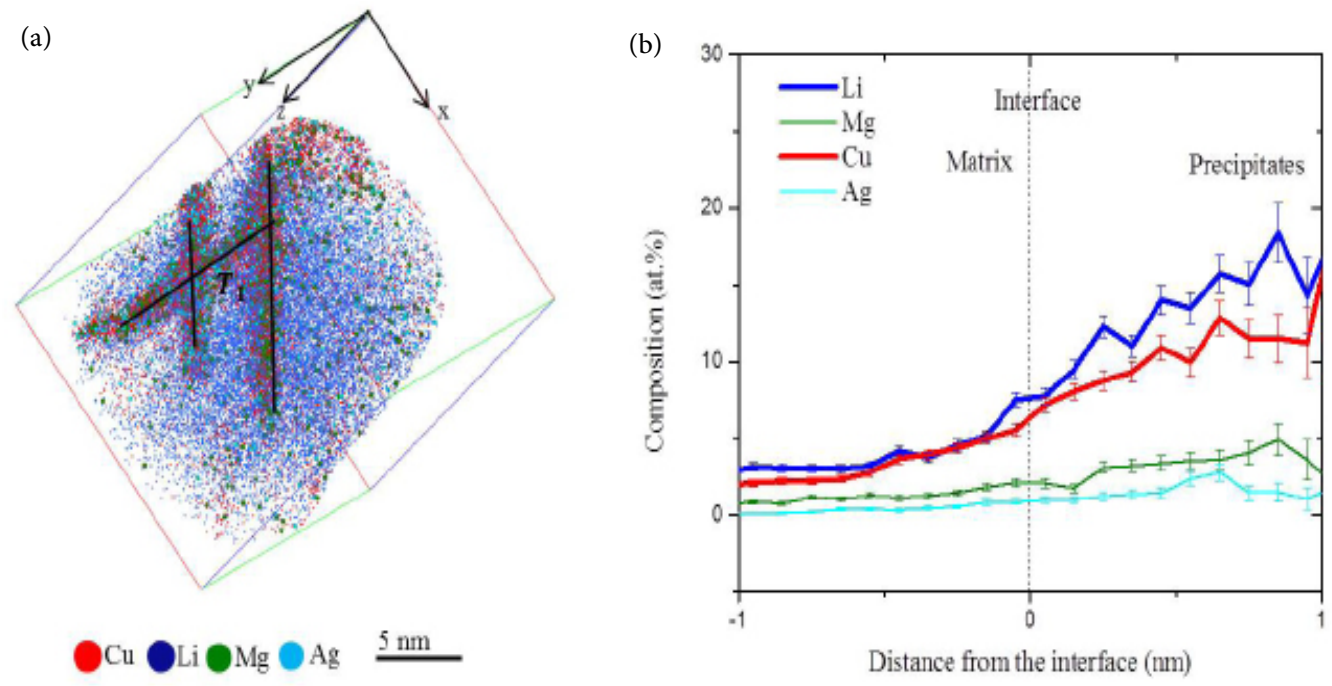

Figure 7: LAWATAP analysis of the sample following T8 heat treatment. (a) The reconstructed volume shows the fine distribution of the $T$, platelets with an average thickness of $(1.4 \pm 0.2) \mathrm{nm}$ and an average length of $(11.8 \pm 2) \mathrm{nm}$, and intersect each other's.(b) The chemical composition as estimated from the concentration composition profile based on the isoconcentration surface containing more than 6 at.\% $\mathrm{Li}$ was estimated to be is $(13 \pm 1)$ at.\% $\mathrm{Li},(11 \pm 1)$ at. $\% \mathrm{Cu},(3 \pm 1)$ at. $\% \mathrm{Mg}$ and $(1.5 \pm 0.4)$ at. $\% \mathrm{Ag}$. 
Citation: Khushaim M, Rothenberger A (2015) Influence of Industrial Heat Treatments on the Precipitation Kinetics of an Al-Cu-Mg-Ag-Zr Alloy. Int J Metall Mater Eng 1: 113. doi: http://dx.doi.org/10.15344/2455-2372/2015/113

Page 7 of 8

et al. [36], the precipitation of the $T_{1}$ phase on the $\{111\}$ Al planes requires the presence of one or more partial dislocations bounded by a stacking fault. Because the stacking fault energy (SFE) of $\mathrm{Al}$ is very high, the dissociation of dislocations into partials, which is believed to be necessary for nucleating the $T_{1}$ phase, can occur. This process can be facilitated by elements known to decrease the SFE of Al; among these elements, $\mathrm{Mg}$ and $\mathrm{Ag}$ have been found to be highly effective [37]. Regarding the effect of $\mathrm{Mg}$ and $\mathrm{Ag}$ enrichment inside the $T_{1}$ platelet on the mechanical properties of the alloy, the single addition of $\mathrm{Ag}$ in $\mathrm{Al}-\mathrm{Cu}-\mathrm{Li}-\mathrm{Zr}$ alloys was found to have no effect on the age hardenable curve, while $\mathrm{Mg}$ addition significantly raises the peak hardness and shortens the time to the peak [19]. The peak hardness further increases when Ag is added together with $\mathrm{Mg}$. This effect is explained as follows. In the case of single addition of $\mathrm{Ag}$, the $T_{1}$ platelet only nucleates on the dislocation loop around a $\mathrm{Zr}$ dispersoid. In contrast, $\mathrm{Mg}$ addition causes the formation of octahedral micro-voids and new GP zones on $\{111\} \mathrm{Al}$ planes; these structures act as nucleation sites for the $T_{1}$ phase, providing a fine dispersion and hence an increase in the hardness of the system. Moreover, the intersection of the $T_{1}$ platelets confirms that theses platelets favor a mechanism to hinder the movement of dislocations resulting in high hardness value (Figure 1). The suppression of dislocations glides by second-phase particles, i.e., $T_{1}$ precipitates in this case, will increase the stress required for the dislocation to move through the particles, which should also increase the yield strength [27].

To follow the precipitation kinetics and phase transformations at the later stage of the aging process, the samples in the T8 heat treatment condition were further aged for $12 \mathrm{~h}$ at $150^{\circ} \mathrm{C}$. The reconstructed volume of this sample after LAWATAP analysis is shown in Figure 8. In this Figure, only one $T$ platelet is observed, with a thickness of $2 \mathrm{~nm}$ and length of $62 \mathrm{~nm}$ in the [111] direction. This phase is also observed to be enriched with $\mathrm{Mg}$ and $\mathrm{Ag}$, which indicates thatboth $\mathrm{Mg}$ and $\mathrm{Ag}$ are associated with coarsening resistance of the $T_{1}$ phase. The small thickness and large length of the observed $T_{1}$ platelet can be explained in terms of the high coherency of the edge of the $T$ precipitates with the $\{111\} \mathrm{Al}$ atomic planes. The final layer of the structure proposed for the $T_{1}$ platelet precipitates is found to have an extremely low lattice mismatch with the $\{111\} \mathrm{Al}$ atomic planes [38]. The observation in Figure 8 confirms that the $T_{1}$ platelet grows via a ledge mechanism [36], whereas both of the board faces of the $T_{1}$ platelet are coherent with the matrix. The value of the measured thickness of this platelet indicates that no thickening of the $T_{1}$ platelet is observed. It is surprising to observe the absence of the $\theta^{\prime}$ platelets in the microstructure. This observation suggests the occurrence of the phase transformation in the form of the dissolution of the $\theta^{\prime}$ phase upon further aging.

\section{Artificially aging of the samples at T6 temper}

Microstructure evaluation at the atomic scale was performed for the sample under the $\mathrm{T} 6$ heat treatment condition. In an effort to accelerate precipitation kinetics without applying plastic deformation, artificial aging is performed at a higher temperature, $180^{\circ} \mathrm{C}$ in this case. After a long aging time of $20 \mathrm{~h}$, the microstructure is found to be predominantly $T_{1}$ platelets (Figure $2 \mathrm{c}$ ). The reconstructed volume of the sample in T6 condition analyzed by LAWATAP is shown in Figure 9. In this case, the microstructure has a uniform distribution of the $T_{1}$ platelets, with an average thickness of $(4.7 \pm 1) \mathrm{nm}$ and an average length of $(40 \pm 2) \mathrm{nm}$, without any indication of their intersection (Figure 9a). A combined proxigram profile corresponding to theses $T_{1}$ platelets, which are delineate by 5 at.\% Li isoconcentration surfaces, is shown in (Figure 9b). As illustrated in this figure, the chemical

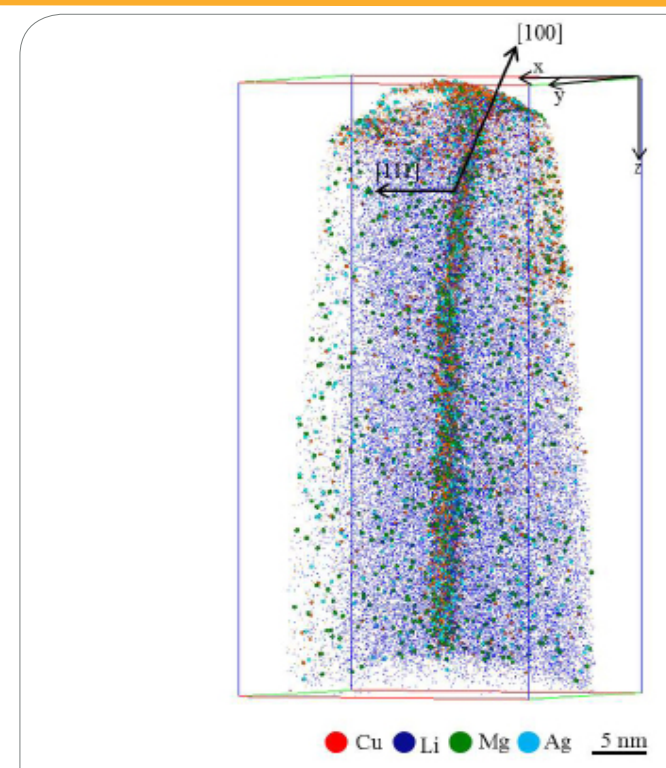

Figure 8: LAWATAP analysis of the sample at the later stage of the aging process shows the growth of the $T_{1}$ platelet via a ledge mechanism and absence of the $\theta^{\prime}$ platelets in the microstructure.

composition of this phase in this temper condition was found to be $(15.7 \pm 1)$ at. $\% \mathrm{Cu},(16.6 \pm 2)$ at.\% $\mathrm{Li},(2.4 \pm 1)$ at. $\% \mathrm{Mg}$ and $(1.4 \pm 0.4)$ at.\% Ag. It is worth notable that the enrichment of the $T_{1}$ phase with $\mathrm{Mg}$ and $\mathrm{Ag}$ is similar to that of the specimen in the $\mathrm{T} 8$ condition. The presence of the $T_{1}$ platelets and their enrichment with $\mathrm{Mg}$ and $\mathrm{Ag}$ are responsible to the age-hardenable behavior under his condition (Figure 1).

Moreover, an inhomogeneous distribution of $\mathrm{Cu}$ and $\mathrm{Mg}$ was observed in the $\mathrm{Al}$ matrix Figure 9c. The locations of $\mathrm{Mg}$-enriched regions coincide with the $\mathrm{Cu}$ - and $\mathrm{Li}$ - enriched regions. Quantitative evolution of these enriched regions was performed through the proxigram composition profile from the isoconcentration surface of 0.5 at.\% $\mathrm{Mg}$ (Figure 9d). According to this proxigram, the chemical composition at these enriched regions was estimated as $(7.1 \pm 3)$ at.\% $\mathrm{Cu},(3.8 \pm 1)$ at.\% $\mathrm{Li},(4.7 \pm 1)$ at. $\% \mathrm{Mg}$ and $(0.5 \pm 0.2)$ at.\% $\mathrm{Ag}$. From this dataset, the growth of the $T_{1}$ platelets in the $\mathrm{Mg}$ enriched region, which contains localized Ag atoms, is clearly observed. This observation suggests the potential role of $\mathrm{Mg}$ and $\mathrm{Ag}$ to catalyze the nucleation of the $T_{1}$ phase. $\mathrm{Mg}$ and $\mathrm{Ag}$ are typically used to increase the number of dissociated dislocations and thus the nucleation sites of the $T_{1}$ phase [39]. Moreover, it has been reported that $\mathrm{Mg}$ atoms enhance the equilibrium vacancy concentration during solution treatment and help to retain these vacancies during the quenching operation. On this basis, the vacancies will provide a dual beneficial effect; enhanced nucleation and increase diffusivity [40]. This effect can be seen clearly in Figure 9c. However, the distribution of these elements in the structure of the $T_{1}$ platelets as well as their portioning between precipitates and matrix is the subject of conflicting reports [41].

\section{Conclusion}

The influence of different industrial heat treatments, namely, the T4, T8 and T6 tempers, on the precipitation kinetics and phase transformation of an Al-Li alloy was investigated. Alloy AA2195 was selected as a model system in the present study. A detailed analysis of the correlation between the microstructure developments due to the respective treatment conditionand the hardening process revealed the following: 
(a)

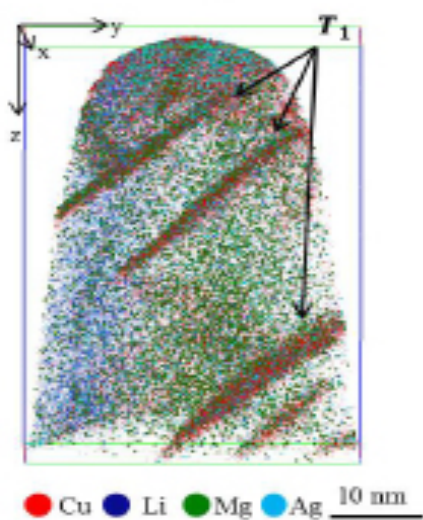

(c)

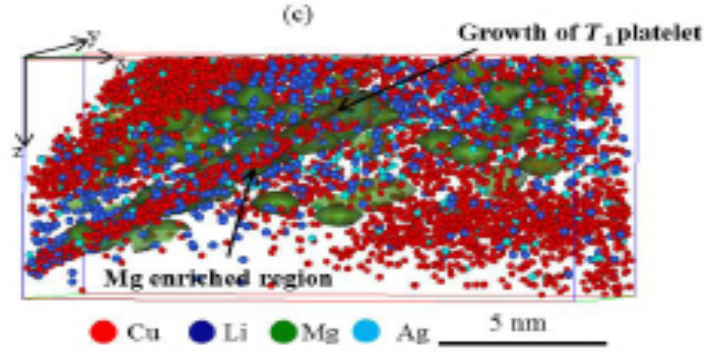

(b)

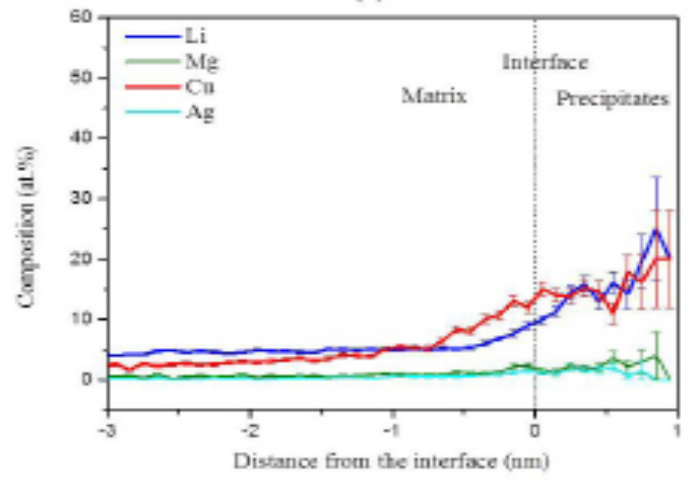

(d)

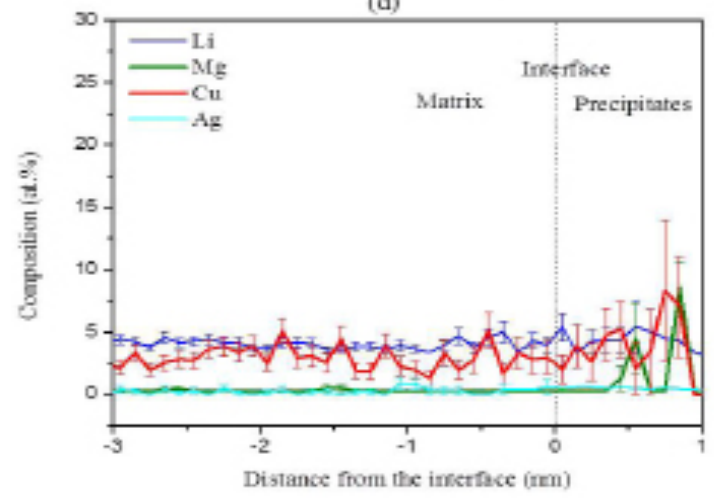

Figure 9: LAWATAP analysis of the sample in T6 condition (a) The reconstructed volume of the microstructure shows a uniform distribution of the T platelets, with an average thickness of $(4.7 \pm 1) \mathrm{nm}$ and an average length of $(40 \pm 2) \mathrm{nm}$. (b) A combined proxigram profile corresponding to the $\mathrm{T}$, platelets, which are delineate by 5 at.\% $\mathrm{Li}$ isoconcentration surfaces, gives the average chemical composition as $(15.7 \pm 1)$ at. $\% \mathrm{Cu},(16.6 \pm 2)$ at. $\% \mathrm{Li},(2.4 \pm 1)$ at. $\% \mathrm{Mg}$ and $(1.4 \pm 0.4)$ at.\% Ag. (c) An inhomogeneous distribution of $\mathrm{Cu}$ and $\mathrm{Mg}$ in the $\mathrm{Al}$ matrix indicates the growth of the $\mathrm{T}_{1}$ platelet in the $\mathrm{Mg}$ enriched region, which contains localized $\mathrm{Ag}$ atoms. (d) Proxigram concentration profile quantifies the chemical composition of the enriched regions in (c) as (7.1 \pm 3$)$ at.\% $\mathrm{Cu}$, (3.8 \pm 1$)$ at. $\% \mathrm{Li},(4.7 \pm 1)$ at. $\% \mathrm{Mg}$ and $(0.5 \pm 0.2)$ at. $\% \mathrm{Ag}$.

1. The microstructure of the sample undergoing the T4 heat treatment reveals the enrichment of the $\beta^{\prime} /$ matrix interface with $\mathrm{Li}, \mathrm{Cu}$ and $\mathrm{Mg}$ atoms. This observation indicates thepotential role of the $\beta^{\prime}$ phase as the nucleation site for the $T_{1}$ phase. The segregation of solute atoms to the $\beta^{\prime} /$ matrix interface was quantified.

2. After conducting the T8 heat treatment, the fine distribution of the $\theta^{\prime}$ and $T_{1}$ phases within the microstructure was observed. The intersections of different platelets were used to suppress the movement of the dislocations, resulting in a high hardness value for the specimen. The growth of the $T_{1}$ platelet precipitate via a ledge mechanism was observed by increasing the aging temperature. The absence of $\theta^{\prime}$ platelets from the microstructure after increasing the aging temperature suggests the occurrence of phase transformation in the form of the dissolution of the $\theta^{\prime}$ phase with increasing aging temperature.

3. With the $\mathrm{T} 6$ heat treatment, the microstructure was dominated by the $T_{1}$ phase, which nucleated on $\mathrm{Mg}$ enriched regions that contain localized $\mathrm{Ag}$ atoms. The $\mathrm{Mg}$ atoms play an important role to enhance the nucleation of the $T_{1}$ phase at this heat treatment condition.

\section{Competing Interests}

The authors have no competing interests with the work presented in this manuscript.

\section{Author Contributions}

Muna Khushaim Conceived the study, performed the experiments, analyzed the data and wrote the paper.

Prof. Alexander Rothenberger supervises the experimental work, reviewed and edited the manuscript.

\section{Acknowledgment}

The Authors thank Judith Seibert (Institute for Physics, University Augsburg,) for her support with transmission electron microscopy. Prof. Talaat Al-Kassab is gratefully acknowledged. M. Khushaim gratefully acknowledges financial support provided through King Abdullah University of Science and Technology (KAUST) base-line funding program.

\section{References}

1. Pickens JR. Heubaum FH, Langan TJ, Kramer LS (1397) In AluminumLithium Alloys. Proc. of the fifth int. Al-Li Conf.1989 (edited by T. H. Sanders and E. A. Starke), MCE publications Ltd., Birmingham, U.K, 1397.

2. Peel C (1986) Aluminum alloys for airframes - limitations and developments. Mater Sci Tech 2: 1169-1175.

3. Starke EA, Staley T (1996) Application of modern aluminum alloys to aircraft. Prog. Aerospace Sci 32: 131-172.

4. Lequeu P, Smith KP, Danielou A (2010) Aluminum-Copper-Lithium Alloy 2050 Developed for Medium to Thick Plate. J Mater Eng Perform 19: 841.

5. Sanders JH (1996) Investigation of Grain Boundary Chemistry in Al-Li 2195 Welds using Auger Electron Spectroscopy. Thin Solid Films 27: 121-127. 
Citation: Khushaim M, Rothenberger A (2015) Influence of Industrial Heat Treatments on the Precipitation Kinetics of an Al-Cu-Mg-Ag-Zr Alloy. Int J Metall Mater Eng 1: 113. doi: http://dx.doi.org/10.15344/2455-2372/2015/113

6. McNamara DK, Pickens JR, Heubaum FH (1992) In: Aluminium-Lithium Alloys. in Proc. 6th Int. Aluminium- Lithium Conf. 1992, DGM.

7. Gayle FW, Heubaum FH, Pickens JR (1989) Al-Li alloys. in proceedings of the fifth international Al-Li conference, (T.H. sander and E.A. Starke, Editors), MCE publications, Birmingham, U.K, 107.

8. Nayan N, Suseelan Nair GK, Mittal MC, Sudhakaran KN (2007) Studies on Al-Cu-Li- Mg-Ag-Zr alloyprocessed through vacuum induction melting (VIM) technique. Mater Sci Eng A 454: 500-507.

9. Gregson PJ, Flower HM (1985) Microstructural control of toughness in aluminum - lithium alloys. Acta Metall 33: 527-537.

10. Ward N, Abad A, Lee EW, Hahn M, Fordan E, et al. (2011) The effects of retrogression and reaging on aluminum alloy 2195. J Mater Eng Perform 20: 1003.

11. Park JK (1988) Influence of retrogression and reaging treatments on the strength and stress corrosion resistance of aluminum alloy 7075-T6. Mater Sci Eng A 103: 223-231.

12. Wang ZM, Shenoy RN (1998) Microstructural Characterization of Aluminum-LithiumAlloys 1460 and 2195. Analytical services and materials. NASA/CR-206914

13. Gayle FW, Vandersande B (1989) Phase transformations in the Al- $\mathrm{Li}-\mathrm{Zr}$ sysyem. Acta Metall 37: 1033.

14. Deschamps A, Brechet $Y$ (1998) Influence of quench and heating rates on the ageing response of an $\mathrm{Al}-\mathrm{Zn}-\mathrm{Mg}-(\mathrm{Zr})$ alloy. Mater Sci Eng A 251 200-207.

15. Wang SC, Starink MJ (2005) Precipitates and intermetallic phases in precipitation hardening $\mathrm{Al}-\mathrm{Cu}-\mathrm{Mg}-(\mathrm{Li})$ based alloys. Int Mater Rev 50 : 193-215.

16. Winkelman GB, Raviprasad K, Muddle BC (2007) Orientation relationships and lattice matching for the $\mathrm{S}$ phase in $\mathrm{Al}-\mathrm{Cu}-\mathrm{Mg}$ alloys. Acta Mater 55 : 3213.

17. Hellman C, Vandenbroucke JA, Rusing J, Isheim D, Seidman DN (2000) Analysis of three - dimensional atom probe data by proximity histogram. Micros Microanal 6: 437-444.

18. Lee KH, Lee YJ, Hiraga K (1998) Precipitation behavior in the early stage of ageing in an $\mathrm{Al}-\mathrm{Li}-\mathrm{Cu}-\mathrm{Mg}-\mathrm{Zr}-\mathrm{Ag}$ (Weldalite 049) alloy. J Mater Res 14: 384-389.

19. Itoh G, Cui Q, Kanno M (1996) Effects of small addition of Magnesium and silver on the precipitation of T1 phase in an $\mathrm{Al}-4 \% \mathrm{Cu}-1.1 \% \mathrm{Li}-0.2 \% \mathrm{Z}$ alloy. Mate Sci Eng A 211: 128.

20. Shenoy RN, Howe JM (1995) A differential scanning calorimetric study of a WeldaliteTM type alloy. Scripta Metall 33: 651- 655.

21. Balmuth ES (1984) Particle size determination in an Al-3Li alloy using DSC Scripta Metallurgica 18: 301.

22. Al-Kassab T, Wollenberger H, Schmitz G, Kirchheim R (2003) Tomography by atom probe field ion microscopy - HighResolution imaging and spectroscopy of materials. Springer Berlin, Heidlberg.

23. Miller MK (2000) Atom Probe Tomography: Analysis at the Atomic Level. Kluwer Academic/ Plenum, New York.

24. Vaumousse D, Cerezo A, Warren PJ (2003) A procedure for quantification of precipitate microstructure from three - dimensional atom probe data. Ultramicroscopy 95: 215- 221.

25. Sha G, Cerezo A (2005) Field ion microscopy and 3-D atom probe analysis of Al3Zr particles in $7050 \mathrm{Al}$ alloy. Ultramicroscopy 102: 151-159.

26. Polmear IJ (1989) Light Alloys.in Metallurgy and Materials Science Series(second ed.), Edward Arnold, London, pp 97.

27. Chen Z, Zhao K, Fan L (2013) Combinitave hardening effects of precipitation in a commerical agerd Al-Cu-Li-X alloy. Mater Sci Eng A 588: 59-64.

28. Vaithyanathan V, Wolverton C, Chen LQ (2002) Multiscale Modeling of Precipitate Microstructure Evolution. Phy Rev Lett 88: 125503.

29. Vaithyanathan V, Wolverton C, Chen LQ (2004) Multiscale modeling of $\theta$ precipitation in Al-Cu binary alloys. Acta Mater 52: 2973.
30. Biswas B, Siegel DJ, Wolverton C, Seidman DN (2011) Precipitates in Al-Cu alloys revisited: Atom-probe tomographic experiments and first-principles calculations of compositional evolution and interfacial segregation. Acta Mater 59: 6187-6204.

31. Ringer SP, Hono K (2000) Microstructural Evolution and Age Hardening in Aluminum Alloys: Atom Probe Field-Ion Microscopy and Transmission Electron Microscopy Studies. Mater Character 44: 101-131.

32. Decreus B, Deschamps A, De Geuser F, Donnadieu P, Sigli, C, et al. (2013) The influence of $\mathrm{Cu} / \mathrm{Li}$ ratio on precipitation in Al-Cu-Li-X alloys. Acta Mater 61: 2207-2218

33. Khan AK, Robinson JS (2008) Effect of cold compression on precipitation and conductivityof an Al-Li-Cu alloy. J Microsc 232: 534-538.

34. Murayama M, Hono K (2001) Role of $\mathrm{Ag}$ and $\mathrm{Mg}$ on precipitation of T1 phase in an Al-Cu-Li-Mg-Ag alloy. Scripta Mater 44: 701-706.

35. Donnadieu P, Shao Y, De Geuser F, Botton GA, Lazar S, et al. (2011) Atomic structure of $\mathrm{T} 1$ precipitates in Al-Li-Cu alloys revisited with HAADFSTEM imaging and small-angle X-ray scattering. Acta Mater 59: 462-472.

36. Cassada WA, Shiflet GJ, Starke EA (1991) The effect of plastic deformation on $\mathrm{Al}_{2} \mathrm{LiCu}$ (T1) precipitation. Metall Trans A 22: 299-306.

37. Schulthess T, Turchi P, Gonis A, Nieh T (1998) Systematic study of stacking fault energies of random Al-based alloys. Acta Mater 46: 2215-2221.

38. Howe JM, Lee J, Vasudévan AK (1998) Structure and deformation behavior of t1 precipitate plates in an Al2 LiCu alloy. Metall Trans A 19: 2911-2920.

39. Gault B, de Geuser F, Bourgeois L, Gabble BM, Ringer SP, et al. (2011) Atom probe tomography and transmission electron microscopy characterisation of precipitation in an $\mathrm{Al}-\mathrm{Cu}-\mathrm{Li}-\mathrm{Mg}-\mathrm{Ag}$ alloy. Ultramicroscopy 111: 683689.

40. Gayle FW (1990) Structure and properties during ageing of ultra-high strength Al-Cu-Li-Ag-Mg alloy. Scripta. Metall et Mater 24: 79-84.

41. Araullo-Peters V, Gault B, De Geuser F, Deschamps A, Cairney JM (2104) Microstructural evolution during ageing of Al-Cu-Li-x alloy. Acta Mater 66: 199-208. 